\title{
Levels and Role of Sucrose Synthase, Sucrose- phosphate Synthase, and Acid Invertase in Sucrose Accumulation in Fruit of Asian Pear
}

\author{
Takaya Moriguchi, Kazuyuki Abe, Tetsuro Sanada, and Shohei Yamaki' \\ Division of Breeding, Fruit Tree Research Station, Tsukuba, Ibaraki, 305 Japan
}

\begin{abstract}
Additional index words. Pyrus, Japanese pear, Chinese pear, sugar composition, cultivars
Abstract. Soluble sugar content and activities of the sucrose-metabolizing enzymes sucrose synthase (SS) (EC 2.4.1.13), sucrose-phosphate synthase (SPS) (EC 2.4.1.14), and acid invertase (EC 2.4.1.26) were analyzed in the pericarp of fruit from pear cultivars that differed in their potential to accumulate sucrose to identify key enzymes involved in sucrose accumulation in Asian pears. The Japanese pear 'Chojuro' [Pyrus pyrifolia (Burro. f.) Nakai] was characterized as a high-sucrose-accumulating type based on the analysis of mature fruit, while the Chinese pear 'Yali' (P. bretschneideri Rehd.) was a low-sucrose-accumulating type throughout all developmental stages. The activity of SS and SPS in 'Chojuro' increased during maturation concomitant with sucrose accumulation, whereas the activity of these enzymes in 'Yali' did not increase during maturation. The activity of SS and SPS in the former were seven and four times, respectively, higher than those in the latter at the mature stage. Further, among 23 pear cultivars, SS activity was closely correlated with sucrose content, while SPS activity was weakly correlated. Soluble acid invertase activity in 'Chojuro' and 'Yali' decreased with fruit maturation, but the relationships between soluble invertase activity and sucrose content were not significant. The results indicate that SS and SPS are important determinants of sucrose accumulation in Asian pear fruit and that a decrease of soluble acid invertase activity is not absolutely required for sucrose accumulation.
\end{abstract}

Sugars are one of the biochemical components of fruit quality. The kind and amount of sugars directly influence fruit flavor components, such as sweetness. Therefore, it is important to determine the sugar components that accumulate in fruit to elucidate enzymes of sugar metabolism and clarify the relationship between the content of accumulated sugar and the activity of some related enzymes as the first step toward the genetic improvement of the quality of pear fruit.

In the family Rosaseae, which includes pear, sorbitol is a major carbohydrate component of translocated photosynthate (Webb and Burley, 1962) and is converted by sorbitol-metabolizing enzymes into other sugars after its transport into the fruit (Hirai, 1982; Negro and Loescher, 1979; Yamaki and Ishikawa, 1986; Yamaki and Moriguchi, 1989). In mature pear fruit of many cultivars, sucrose, glucose, fructose, and sorbitol are the major storage sugars (Kajiura et al., 1979; Yamiki and Moriguchi, 1989). In Japanese pear (Yamaki and Moriguchi, 1989) and apple (Yamaki and Ishikawa, 1986), fructose and glucose are mainly produced from sorbitol by the enzymes $\mathrm{NAD}^{+}$-dependent sorbitol dehydrogenase ( $\left.\mathrm{NAD}^{+}-\mathrm{SDH}\right)$ and sorbitol oxidase, respectively. However, there is less information concerning sucrose accumulation in pear fruit, although an inverse relationship between acid invertase activity and sucrose content in Japanese pear fruit (Yamaki et al., 1979) and an increase in SS activity with sucrose accumulation in European pear fruit (Latché et al., 1975) have been reported.

Kajiura et al. (1979) reported that the composition of individual sugar differs among pear cultivars and classified the East Asian pears into six groups using principal component analysis of their sugar composition. They defined 'Chojuro', 'Nijis-

\footnotetext{
Received for publication 2 May 1991. Accepted for publication 28 Oct. 1991. Contribution no. A-281 of the Fruit Tree Research Station. We thank S. Hayashi for assistance in conducting the present study and members of Breeding 2nd Laboratory for kind suggestions. The cost of publishing this paper was defrayed in part by the payment of page charges. Under postal regulations, this paper therefore must be hereby marked advertisement solely to indicate this fact. 'Present address: Laboratory of Horticulture, School of Agriculture, Nagoya Univ., Chikusa, Nagoya, 464 Japan.
}

seiki', and 'Kinchaku' as high-sucrose-accumulating types and 'Yali', 'Laiyangcili', and 'Wowoli' as low-sucrose-accumulating types. This grouping may indicate that the activity of enzymes synthesizing or catabolizing sucrose differs among pear cultivars. In muskmelon (Cucumis melo L.), Hubbard et al. (1989) showed that SPS activity was closely correlated to sucrose content. However, in peach [Prunus persica (L.) Batsch] fruit, Moriguchi et al. (1990) suggested a predominant role for SS, rather than SPS, in sucrose accumulation by peach.

The purpose of the present study was to examine the relationship between the activity of enzymes metabolizing sucrose and the content of accumulated sucrose to clarify the key enzymes involved in sucrose accumulation in pear fruit.

\section{Materials and Methods}

Fruit samples. Samples of 10 to 20 fruit were harvested from either 'Chojuro' Japanese pear or 'Yali' Chinese pear throughout the 1989 season. For the other 21 cultivars, samples were harvested at the mature fruit stage only. Development of fruit was based on days after full bloom and a color chart (Kajiura et al., 1975). A portion of each fruit was diced into small pieces and used for enzyme assays and sugar determination. All enzyme assays and sugar determinations were carried out on duplicated samples.

Determination of sugar content and composition. Sugars were extracted by grinding flesh tissues (10 g fresh weight) in $80 \%$ ethanol, adjusted to $\mathrm{pH} 7.0$ with $0.1 \mathrm{~N} \mathrm{NaOH}$, and heated for $5 \mathrm{~min}$ at $80 \mathrm{C}$. The extraction was repeated three times. The combined extract corresponding to $0.5 \mathrm{~g}$ fresh weight was dried in vacuo and redissolved in water. The solution was passed through an ion-exchange column (Dowex 50W-X8 and Dowex $1-\mathrm{X} 8)$. An aliquot $(10 \mu \mathrm{l})$ of the eluate was analyzed by highperformance liquid chromatography (Shimadzu LC-6A; Kyoto, Japan), which was equipped with a RI detector and a SP1010

Abbreviations: DTT, dithiothreitol; NAD+-SDH, NAD+-dependent sorbitol dehydrogenase; SPS, sucrose-phosphate synthase; SS, sucrose synthase. 
column (Showa Denko K. K., Tokyo). Water was used as the carrier solvent at a flow rate of $0.5 \mathrm{ml} \cdot \mathrm{min}^{-1}$.

Enzyme extraction and assays. SS and SPS were extracted by homogenizing fresh pear fruit $(10 \mathrm{~g}$ for young fruitlets of 'Chujuro' and 'Yali'; up to $50 \mathrm{~g}$ for, mature fruit of all pear cultivars, depending on developmental stage) in a ratio of 1 fruit $: 5(\mathrm{w} / \mathrm{v}) 0.2 \mathrm{M} \mathrm{K}$-phosphate buffer (pH. 7.8) containing $10 \mathrm{~mm}$ $\mathrm{K}$-ascorbate, $5 \mathrm{~mm} \mathrm{MgCl}_{2}, 1 \mathrm{mM}$ dithiothreitol (DTT), and $10 \%$ polyvinylpyrrlidone (insoluble). After centrifugation at $12,000 \times$ $\mathrm{g}$ for $20 \mathrm{~min}$, a portion of the supernatant was dialyzed for up to $10 \mathrm{~h}$ at $4 \mathrm{C}$ against $10 \mathrm{~mm}$ Tris. $\mathrm{HCl}$ buffer $(\mathrm{pH}$ 7.2) containing $1 \mathrm{~mm}$ DTT.

For further purification of SS, the supernatant was adjusted to $80 \%$ saturation with ammonium sulfate, then centrifuged at $12,000 \mathrm{x} \mathrm{g}$ for $10 \mathrm{~min}$. The precipitate was dissolved in a small volume of $5 \mathrm{~mm}$ Tris $\cdot \mathrm{HCl}$ buffer $(\mathrm{pH} 7.5)$ containing $0.2 \mathrm{~mm}$ EDTA and 2 mM 2-mercaptoethanol (buffer A), dialyzed against the same buffer overnight, and applied to a column $\left(3 \mathrm{~cm}^{2} \times\right.$ $15 \mathrm{~cm}$ ) of DEAE-cellulose (DE-52) that had previously been equilibrated with buffer $A$. The column was washed with buffer $\mathrm{A}$, and SS was eluted by $0.5 \mathrm{M} \mathrm{KC1}$ in buffer A. After the eluate was concentrated in a collodion bag, the solution was applied to a column $\left(2 \mathrm{~cm}^{2} \times 78 \mathrm{~cm}\right)$ of Sepharose CL-6B that had been equilibrated with $25 \mathrm{~mm}$ Tris $\cdot \mathrm{HCl}$ buffer $(\mathrm{pH} 7.5)$ containing $1 \mathrm{~mm}$ EDTA and $5 \mathrm{~mm}$ 2-mercaptoethanol, then eluted by the same buffer. Fractions containing SS activity were collected and used for kinetics.

Acid invertase was extracted by homogenizing pear fruit in 0.1 м K-phosphate buffer ( $\mathrm{pH} 7.0$ ) containing $10 \mathrm{~mm} \mathrm{~K}$-ascorbate and $1 \mathrm{~mm}$ DTT. After centrifugation at $12,000 \times \mathrm{g}$ for 20 rein, the precipitate was washed again with the same buffer, then recentrifuged at $12,000 \times \mathrm{g}$ for $20 \mathrm{~min}$. The combined supernatant (soluble form) and the residue (bound form) remaining after centrifugation were dialyzed against $10 \mathrm{~mm}$ Tris- $\mathrm{HCl}$ buffer ( $\mathrm{pH}$ 7.2) containing $1 \mathrm{~mm}$ DTT. Unless otherwise noted, all procedures were conducted at $4 \mathrm{C}$.

SS and SPS activity were assayed by the method described by Moriguchi et al. (1990), For SS activity, reaction mixtures contained 15 mM Hepes-KOH buffer ( $\mathrm{pH}$ 8.5), 2 mM UDPglucose, $15 \mathrm{~mm}$ fructose, $5 \mathrm{mM} \mathrm{MgCl}_{2}$, and the appropriate volume of sample. For SPS activity, $15 \mathrm{~mm}$ fructose-6-phosphate and $15 \mathrm{~mm}$ Hepes-KOH buffer $(\mathrm{pH} 7.5)$ were substituted for $15 \mathrm{~mm}$ fructose and $15 \mathrm{~mm}$ Hepes-KOH buffer ( $\mathrm{pH} 8.5)$, repsectively. In addition, $1.3 \mathrm{~mm} \mathrm{NaF}$ was added to the reaction mixture. Sucrose or sucrose-P was determined by the method of Roe (1934). Data are expressed as micromoles of sucrose or sucrose-P produced per gram of fresh weight per hour.

The role of SPS in sucrose synthesis has been demonstrated in many plant materials, including fruit (Hubbard et al., 1989; Lowell et al., 1989). As SPS is a labile enzyme, careful extraction is essential (Hubbard et al., 1989). Therefore, the extraction procedures, especially the desalting method, were compared (Table 1). Samples assayed according to the method of Hubbard et al. (1989), where desalting was followed immediately by ultrafiltration or gel filtration, had slightly higher SPS activity than samples desalted and assayed by the methods we used. The amount of glucose-6-phosphate produced by hexose phosphate isomerase in the present assay system was $<1$ $\mathrm{mm}$, although the content varied among samples. Therefore, the addition of glucose-6-phosphate might result in a slight increase of SPS activity. In contrast, since fructose-6-phosphate concentration was high in this study, the effect of glucose-6-phosphate might be expected to be small (Doehlert and Huber, 1983). In
Table 1. Effect of extracting method and reaction mixtures on the activity of SPS from 'Choju' pear fruit.

\begin{tabular}{lcc}
\hline \multirow{2}{*}{ Method } & \multicolumn{2}{c}{ Activity $\left(\mu \mathrm{mol} \cdot \mathrm{g}^{-1}\right.$ fresh wt $)$} \\
\cline { 2 - 3 } $\mathrm{I}^{\mathrm{x}}$ & Expt. $1^{\mathrm{z}}$ & Expt. $2^{y}$ \\
$\mathrm{II}^{\mathrm{w}}$ & $2.71 \pm 1.07$ & $2.10 \pm 0.22$ \\
\hline
\end{tabular}

${ }^{2}$ Average from two replications.

${ }^{y}$ Average from four replications.

'Sample was desalted immediately by gel filtration or ultrafiltration and assayed with reaction mixtures according to Hubbard et al. (1989). wesalting method and reaction mixtures described in this paper were used.

addition, the concentration of fructose-6-phosphate would not have fallen dangerously below the concentration indicating Vmax by the addition of $\mathrm{NaF}$. Thus, we used the procedures described here because of the ease in handling many samples simultaneously.

For kinetic values of partially purified SS, the activity related to the synthesis of sucrose was assayed by an enzyme-coupling method for UDP, according to a slight modification of the procedure reported by Moriguchi and Yamaki (1988). Reaction mixtures contained $15 \mathrm{~mm}$ Hepes-KOH buffer $(\mathrm{pH} 8.5)$, various concentrations of fructose and UDP-glucose, $5 \mathrm{mM} \mathrm{MgCl}_{2}, 4$ mM phosphoenolpyruvate, $0.15 \mathrm{~mm} \mathrm{NADH}, 20 \mathrm{~mm} \mathrm{KC1}, 13$ $\mu \mathrm{g}$ pyruvate kinase, $13 \mu \mathrm{g}$ lactate dehydrogenase, and the sample. The activity related to the cleavage of sucrose was assayed by the amount of UDP-glucose coupled to the reduction of NAD in the presence of excess UDP-glucose dehydrogenase according to a slight modification of the procedure of Morell and Copeland (1985). Reaction mixtures contained 15 mM Hepes$\mathrm{KOH}$ buffer ( $\mathrm{pH} 7.5$ ), various concentrations of sucrose and UDP, $1.5 \mathrm{~mm}$ NAD, 0.03 U UDP-glucose dehydrogenase, and the sample.

Acid invertase was assayed in a reaction mixture consisting of $75 \mathrm{~mm}$ acetate buffer ( $\mathrm{pH} 5.0$ ), $95 \mathrm{~mm}$ sucrose, and the appropriate volume of sample. The mixture was incubated at $30 \mathrm{C}$ for $20 \mathrm{~min}$. The amount of reducing sugar liberated was determined by the method of Nelson (1944). Data are expressed as micromoles of reducing sugar produced per gram of fresh weight per hour.

\section{Results}

Sugar content. The sugar content of Japanese ('Chojuro') and Chinese ('Yali') pear fruit was determined throughout their development (Fig. 1). In 'Chojuro', sorbitol was the predominant sugar, accounting for $\approx 80 \%$ of the total sugars present in the early stages of fruit growth. Fructose and glucose began to accumulate around mid-July, then constituted $\approx 25 \%$ and $7 \%$,respectively, of the total sugars present in mature fruit. Sucrose increased rapidly during fruit maturation (late August) and comprised $\approx 53 \%$ of the total sugars. As a result, sugar content in the mature fruit (early September) was about four times higher than that of the young fruitlets (late May).

In 'Yali', sorbitol was also a predominant sugar in young fruitlets and remained at high levels $\approx 24 \mathrm{mg} \cdot \mathrm{g}^{-1}$ fresh weight) throughout the season. Fructose concentration increased gradually with fruit growth and eventually comprised $\approx 45 \%$ of the total sugars. Glucose and sucrose were minor components and increased only slightly during fruit growth and maturation, and as a result comprised only $16 \%$ and $8 \%$, respectively, of the total sugars in mature fruit. 


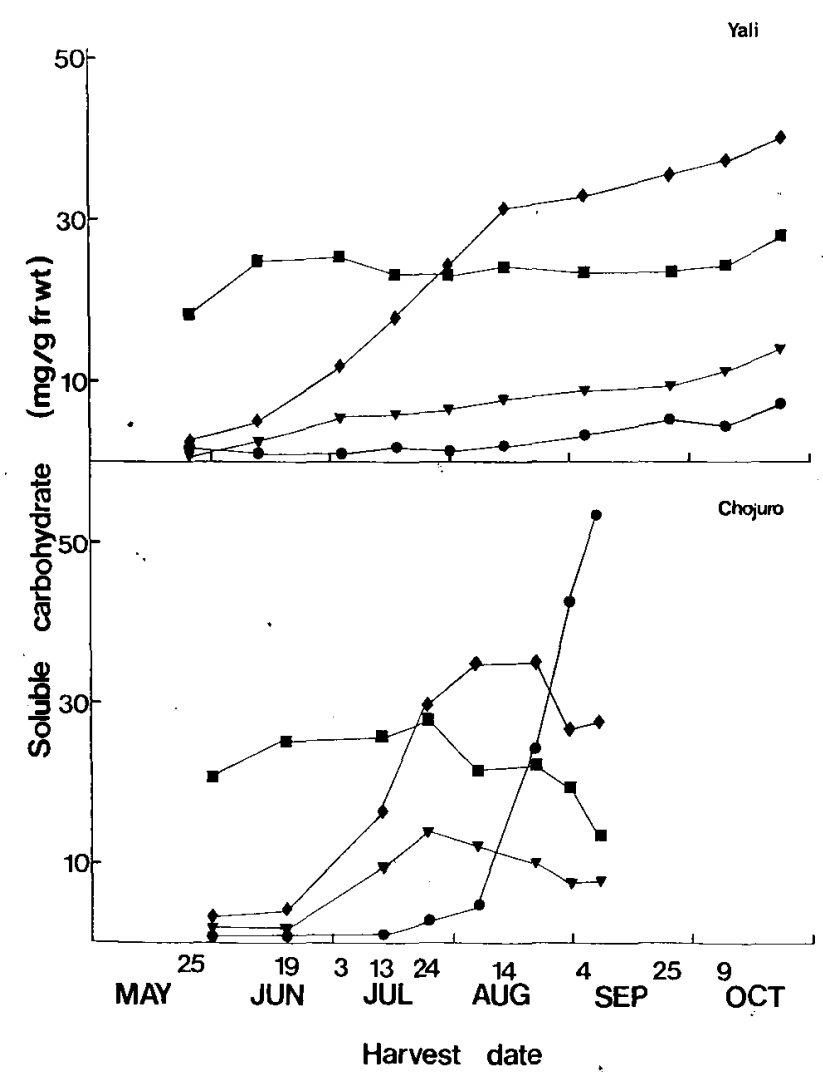

Fig. 1. Seasonal change in soluble sugars of pear fruit. (•) Sucrose, $(\nabla)$ glucose, (•) fructose, (घ) sorbitol.

SS, SPS, and acid invertase activity. SS activity in 'Chojuro' was highest in fruitlets (late May), and then decreased; it was at low levels during the initial stages of fruit growth, but increased rapidly concomitant with sucrose accumulation during fruit maturation (Fig. 2A). In contrast, although the profile of seasonal changes in SS activity in 'Yali' was the same as that of 'Chojuro' during the early stage of fruit growth, there was no increase in SS activity during fruit maturation.

Activity of SPS in 'Chojuro' was low during the fruitlet stages of fruit growth, then rose markedly with fruit maturation (Fig. 2B). However, in 'Yali', SPS activity did not rise markedly with fruit maturation, although the profile of seasonal changes in activity was the same as that of 'Chojuro' during the initial stages of growth.

Acid invertase was composed of two types, soluble and bound. Soluble invertase activity was predominant throughout development in both cultivars. Acid invertase activity in 'Chojuro' was high in the early stages (Fig. 2C). Thereafter, activity decreased rapidly, and as a result, the activity in mature fruit was about one-fourteenth of that in fruitlets. In 'Yali', invertase activity was highest at the end of May and then decreased with fruit development, but the reduction in activity was less than that in 'Chojuro'.

Correlation between enzyme activity and sucrose content in mature pear fruits. In general, cultivars that accumulate high levels of sucrose had relatively higher activity of SS and SPS than cultivars that accumulate little sucrose (Table 2). A positive correlation existed between SS $(r=0.633, P=0.01)$ (Fig. 3) and SPS ( $\mathrm{r}=0.445, P=0.05$ ) (Fig. 4) and sucrose content. Further, a positive correlation was also noted between sucrose content and the combined activity of the sucrose-synthesizing enzymes $(\mathrm{SS}+\mathrm{SPS})(\mathrm{r}=0.584, P=0.01)$ (detailed data

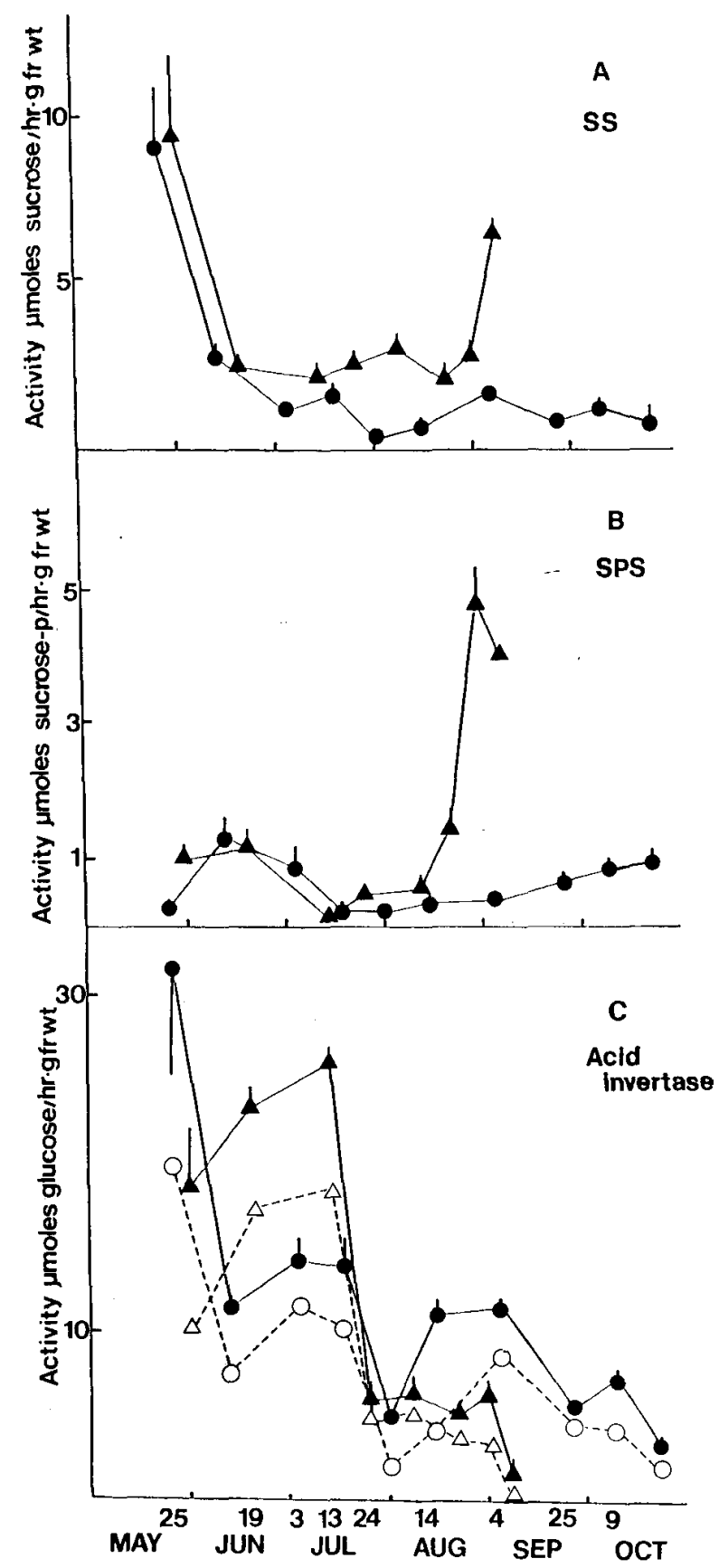

Harvest date

Fig. 2. Seasonal change in SS, SPS, and acid invertase activity in pear fruit. (A) SS activity in 'Chojuro' (A) and 'Yali' (•). (B) SPS

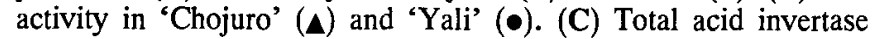
activity (soluble and bound forms) in 'Chojuro' $(-\mathbf{\Delta -})$ and 'Yali' $(-\bullet-)$. Soluble acid in invertase activity in 'Chojuro' (-- --$)$, and 'Yali' (--O--). Each point is mean \pm SE of two experiments.

not shown). The activity of acid invertase varied greatly among the cultivars. Soluble invertase is considered to function mainly in the breakdown of sucrose in the vacuole. However, the correlation between soluble invertase activity and sucrose content was not significant $(r=-0.400)$. The activity of total invertase activity (soluble and bound forms) showed a weak negative correlation with sucrose content $(r=-0.417, P=0.05)$.

Kinetic values of partially purified SS from pear. Kinetic values of SS were determined in the Japanese pear cultivars 
Table 2. Enzyme activity and individual sugars in mature fruits of some pear cultivars.

\begin{tabular}{|c|c|c|c|c|c|c|c|c|}
\hline \multirow[b]{2}{*}{ Cultivar } & \multicolumn{4}{|c|}{ Enzyme activity $\left(\mu \mathrm{mol} \cdot \mathrm{h}^{-1} \cdot \mathrm{g}^{-1}\right.$ fresh wt) } & \multicolumn{4}{|c|}{ Individual sugar ${ }^{2}\left(\mathrm{mg} \cdot \mathrm{g}^{-1}\right.$ fresh $\left.\mathrm{wt}\right)$} \\
\hline & SS & SPS & S-INVy & $(\mathrm{INV})^{\mathrm{x}}$ & SUC & FRU & GLU & SOR \\
\hline \multicolumn{9}{|c|}{ Pyrus pyrifolia (Japanese pear) } \\
\hline 1. Okuroku & $6.6+0.8$ & $5.9 \pm 0.1$ & $2.6 \pm 0.5$ & $(3.0 \pm 0.9)$ & 23.5 & 42.3 & 13.7 & 9.3 \\
\hline 2. Kinchaku & $9.8 \pm 0.5$ & $6.1 \pm 0.6$ & $1.2 \pm 0.5$ & $(3.9 \pm 0.1)$ & 35.8 & 30.1 & 6.5 & 12.3 \\
\hline 3. Shirayuki & $1.2 \pm 0.2$ & $1.8 \pm 1.1$ & $2.4 \pm 0.1$ & $(2.4 \pm 0.1)$ & 2.5 & 25.2 & 5.6 & 9.2 \\
\hline 4. Imamuraaki & $2.3 \pm 0.6$ & $0.9 \pm 0.3$ & $1.3 \pm 0.2$ & $(1.8 \pm 0.4)$ & 9.0 & 43.2 & 12.0 & 9.5 \\
\hline 5. Tosanashi & $1.8 \pm 0.4$ & $1.2 \pm 0.3$ & $1.9 \pm 0.4$ & $(1.9 \pm 0.4)$ & 17.1 & 52.4 & 3.1 & 6.1 \\
\hline 6. Yokogoshi & $2.3 \pm 0.4$ & $2.1 \pm 0.9$ & $4.6 \pm 0.5$ & $(7.6 \pm 0.6)$ & 2.2 & 34.0 & 6.4 & 25.5 \\
\hline 7. Ruisan & $2.7 \pm 0.1$ & $1.2 \pm 0.3$ & $12.4 \pm 0.9$ & $(14.1 \pm 0.5)$ & 2.0 & 46.1 & 12.9 & 21.5 \\
\hline 8. Meigetsu & $2.1 \pm 1.0$ & $2.0 \pm 0.3$ & $2.2 \pm 1.8$ & $(3.2 \pm 0.9)$ & 13.9 & 40.3 & 10.3 & 13.1 \\
\hline 9. Konpeito & $3.1 \pm 1.5$ & $1.1 \pm 0.3$ & $1.0 \pm 0$ & $(1.0 \pm 0)$ & 50.6 & 25.8 & 7.5 & 19.7 \\
\hline 10.Shinchu & $5.3 \pm 0.4$ & $2.3 \pm 0.7$ & $3.1 \pm 0.8$ & $(4.0 \pm 0.3)$ & 45.5 & 20.3 & 8.6 & 11.9 \\
\hline 11. Nijìsseiki & $3.5 \pm 0.2$ & $4.3 \pm 1.5$ & $2.5 \pm 0.9$ & $(3.2 \pm 0.8)$ & 44.6 & 31.8 & 7.2 & 9.7 \\
\hline 12. Chojuro & $6.5 \pm 0.1$ & $3.9 \pm 0.1$ & $0 \pm 0$ & $(1.3 \pm 0.2)$ & 57.1 & 27.0 & 7.1 & 15.2 \\
\hline 13. Hakuteiryu & $2.0 \pm 0.2$ & $1.6 \pm 0.6$ & $3.2 \pm 0.2$ & $(3.2 \pm 0.2)$ & 2.7 & 46.9 & 21.1 & 24.0 \\
\hline 14. Kikusui & $5.4 \pm 1.0$ & $4.3 \pm 0.5$ & $0.4 \pm 0.3$ & $(5.5 \pm 1.5)$ & 21.0 & 46.4 & 8.2 & 16.2 \\
\hline 15. Kosui & $4.7 \pm 1.5$ & $2.4 \pm 1.8$ & $2.7 \pm 0.3$ & $(3.4 \pm 0.3)$ & 32.4 & 45.8 & 13.8 & 16.5 . \\
\hline 16. Hosui & $5.1 \pm 1.0$ & $2.6 \pm 0.6$ & $3.4 \pm 0$ & $(3.6 \pm 0.2)$ & 45.5 & 42.2 & 15.1 & 19.9 \\
\hline 17. Hakko & $5.7 \pm 0.5$ & $1.1 \pm 0.3$ & $4.7 \pm 2.5$ & $(6.3 \pm 2.0)$ & 18.0 & 29.5 & 12.8 & 16.5 \\
\hline 18. Choju & $4.4 \pm 0.1$ & $2.3 \pm 1.8$ & $0 \pm 0$ & $(0.5 \pm 0)$ & 26.3 & 49.2 & 19.4 & 24.3 \\
\hline \multicolumn{9}{|c|}{ Pyrus bretschneideri (Chinese pear) } \\
\hline 19. Wowoli & $1.4 \pm 0.2$ & $1.0 \pm 0.2$ & $6.4 \pm 0$ & $(7.2 \pm 0.2)$ & 3.0 & 43.8 & 16.5 & 17.0 \\
\hline 20. Laiyangcili & $1.9 \pm 0.3$ & $1.4 \pm 0.2$ & $0 \pm 0$ & $(1.6 \pm 0.2)$ & 4.4 & 57.1 & 14.4 & 25.0 \\
\hline 21. Yali & $0.8 \pm 0.3$ & $0.9 \pm 0.1$ & $2.2 \pm 0$ & $(3.9 \pm 0.2)$ & 7.5 & 40.5 & 14.5 & 28.0 \\
\hline \multicolumn{9}{|c|}{ Hybrids (Chinese pear $\times$ Japanese pear) } \\
\hline 22. Hattatasu & $1.9 \pm 0.1$ & $2.7 \pm 0.2$ & $5.0 \pm 1.0$ & $(5.0 \pm 1.0)$ & 16.7 & 51.3 & 20.5 & 9.2 \\
\hline 22. Ninomiyahakuri & $7.1 \pm 1.1$ & $7.5 \pm 1.1$ & $0.5 \pm 0.1$ & $(0.6 \pm 0.1)$ & 31.9 & 33.5 & 7.1 & 13.0 \\
\hline
\end{tabular}

${ }^{2}$ SUC $=$ sucrose; FRU = fructose; GLU = glucose; SOR = sorbitol.

yActivity of soluble form of acid invertase.

xTotal activity (soluble and bound forms) of acid invertase.

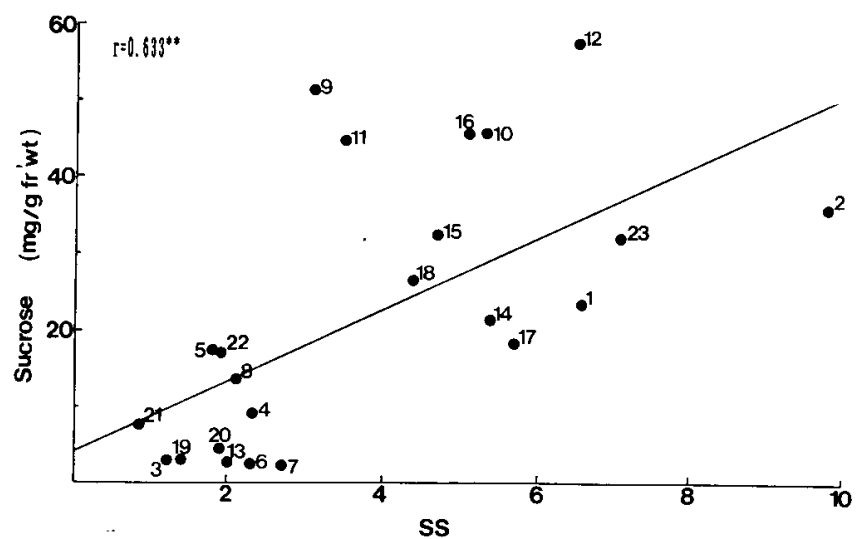

Fig. 3. Relationship between sucrose content and SS activity. Each point indicates an individual pear cultivar as listed in Table 2.

Choju and Shinchu. In 'Choju' and 'Shinchu', Km values for fructose were 3.2 and $1.9 \mathrm{~mm}$, and for UDP-glucose were 0.086 and $0.022 \mathrm{~mm}$, respectively, in the direction of sucrose synthesis. In the sucrose cleavage direction, $\mathrm{Km}$ values for sucrose were 16.3 and $11.2 \mathrm{~mm}$, and 0.076 and $0.024 \mathrm{~mm}$ for UDP in 'Choju' and 'Shinchu', respectively. Vmax values for fructose and UDP-glucose (3.3 and 3.2 nmole product/rein) were larger than for sucrose and UDP (2.2 and 2.5 nmole product/rein) in 'Choju'. Also, in 'Shinchu', Vmax values for fructose and UDPglucose (3.3 and 3.1 nmole product/rein) were about three times larger than those for sucrose and UDP (1.1 and 0.9 nmole product/rein).

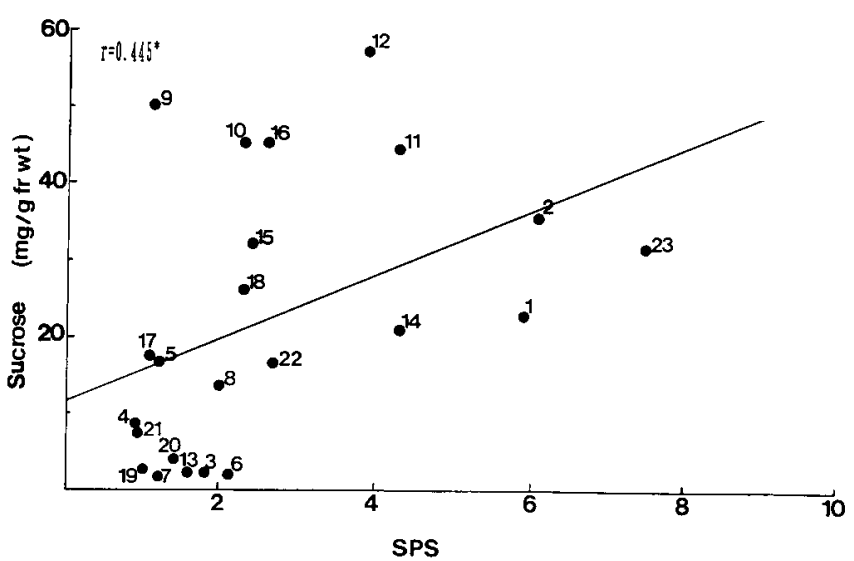

Fig. 4. Relationship between sucrose content and SPS activity. Each point indicates an individual pear cultivar as listed in Table 2.

\section{Discussion}

Sorbitol is actively converted into other sugars after its unloading in the fruit of Rosaceae (Moriguchi et al., 1990; Yamaki and Moriguchi, 1989). The Japanese pear cultivar Chojuro accumulated little sucrose during the fruitlet stage of growth, but, thereafter, sucrose accumulated. This apparent metabolic shift was accompanied by an increase in SS and SPS activity. Latché et al. (1975) also reported the coincidence of sucrose accumulation with an increase in SS activity in European pear fruit. In contrast to 'Chojuro', the Chinese pear cultivar Yali accumulated little sucrose throughout the season, and the activity of SS 
and SPS did not increase but remained relatively constant during fruit maturation.

SS has been reported to have a role in sucrose cleavage rather than sucrose synthesis (Hawker, 1985; Turner and Turner, 1975). However, based on the results of seasonal fluctuations in SS activity and sucrose content (Moriguchi et al., 1990) and of the kinetic analysis of purified SS (Moriguchi and Yamaki, 1988), we suggest that $\mathrm{SS}$ is involved in sucrose synthesis in mature peach fruit that accumulates relatively high levels of sucrose. In pear fruit, SS also appears to be involved in sucrose synthesis, since SS activity increased with sucrose accumulation. Kinetic values of partially purified SS using two cultivars were examined. In 'Choju' and 'Shinchu', $K m$ values for fructose were one-third or less than those for sucrose. Also, Vmax values in the direction of sucrose synthesis were larger than those in the direction of sucrose cleavage in both cultivars. Thus, these results suggest that $\mathrm{SS}$ had a higher affinity for substrate in sucrose synthesis than in sucrose cleavage. This tendency was similar to that of SS purified from peach fruit (Moriguchi and Yamaki, 1988). Further, there was a close correlation between SS activity and sucrose accumulation (Fig. 3). Schaffer et al. (1987) suggested a similar role for SS in Cucumis fruit by comparing the activity of SS in sweet melon fruit accumulating sucrose with that in nonsweet melon fruit accumulating only low levels of sucrose.

In our study of pear fruit, the high levels of sucrose production cannot be explained by the function of SPS only, as a weak correlation (Fig. 4) between sucrose content and SPS activity was observed. Thus, we suggest that sucrose accumulation during maturation of Japanese pear may be due to SS activity and SPS activity. This conclusion is supported by the result that the activity of sucrose-synthesizing enzymes (SS + SPS) correlated positively with sucrose content accumulated in fruit.

Although both acid and neutral invertase were present in Japanese pear fruit, neutral invertase activity is very low (Yamaki et al., 1979). Therefore, only acid invertase activity was considered in the present experiment. Tissues that accumulate sucrose have been characterized by a loss of acid invertase activity (Giaquinta, 1979; Hatchet al., 1963; Kato and Kubota, 1978; Ricardo and ap Rees, 1970). That is, the loss of acid invertase activity seems to be a prerequisite for sucrose accumulation. High activity of acid invertase has also been shown to be retained in storage tissues accumulating no sucrose, for example, in tomato (Lycopersicon esculentum Mill.) fruit (Manning and Maw, 1975) and radish (Raphanus sativus L.) and turnip roots (Brassica rapa L.) (Ricardo and Sovia, 1974). In 'Chojuro', it may be possible that sucrose accumulation became more efficient as acid invertase activity declined. However, in 'Yali', invertase activity also decreased during growth and maturation, despite the accumulation of little sucrose. No significant correlation between soluble invertase activity and sucrose content was obtained. Therefore, it remains unclear whether sucrose accumulation in Asian pear fruit requires the reduction of acid invertase activity. Thus, we propose that SS and SPS is a major participant in sucrose accumulation in Asian pear fruit, and the loss of soluble acid invertase activity is not absolutely required for sugar accumulation.

\section{Literature Cited}

Doehlert, D. and S.C. Huber. 1983. Regulation of spinach leaf sucrose phosphate synthase by glucose-6-phosphate, inorganic phosphate, and pH. Plant Physiol. 73:989-994.
Giaquinta, R. 1979. Sucrose translocation and storage in the sugar beet. Plant Physiol. 63:828-832.

Hatch, M. D., J.A. Sacher, and K.T. Glasziou. 1963. Sugar accumulation cycle in sugar cane. I. Studies on enzymes of the cycle. Plant Physiol. 38:338-343.

Hawker, J.S. 1985. Sucrose, p. 1-51. In: P.M. Dey and R.A. Dixon (eds.). Biochemistry of storage carbohydrates in green plants. Academic, New York.

Harai, M. 1982. Accelerated sugar accumulation and ripening of Ioquat fruit exogenously applied ethylene. J. Jpn. Soc. Hort. Sci. 51:159-164.

Hubbard, N. L., S.C. Huber, and D.M. Pharr. 1989. Suerose phosphate synthase and acid invertase as determinants of sucrose concentration in developing muskmelon (Cucumis melo L.) fruits. Plant Physiol. 91:15271534.

Kajiura, I., K. Suzuki, and T. Yamazaki. 1975. Color chart for Japanese pear (Pyrus serotina var. culta Rehder). HortScience 10:257-258.

Kajiura, I., S. Yamaki, M. Omura, T. Mlhama, and Y. Machida. 1979. Improvement of sugar content and composition in fruits, and classifications of east Asian pears by the principal component analysis of sugar compositions in fruits. (in Japanese with English summary) Jpn. J. Breed. 29:1-12.

Kate, T. and S. Kubota. 1978. Properties of invertases in sugar storage tissues of citrus fruit and changes in their activities during maturation. Physiol. Plant. 42:67-72.

Latché, A., J.C. Pech, and J. Fallot. 1975. Amylolyse et maturation chez la pomme et la poire. Physiol. Veg. 13:637-649.

Lowell, C.A., P.T. Tomlinson, and K.E. Koch. 1989. Sucrose-metabolizing enzymes in transport tissues and adjacent sink structures in developing citrus fruit. Plant Physiol. 90:1394-1402.

Manning, K. and G.A. Maw. 1975. Distribution of acid invertase in the tomato plant. Photochemistry 14:1965-1969.

Morell, M. and L. Copeland. 1985. Sucrose synthase of soybean nodules. Plant Physiol. 78:149-154.

Moriguchi, T. and S. Yamaki 1988. Purification and characterization of sucrose synthase from peach (Prunus persica) fruit. Plant Cell Physiol 29:1361-1366.

Moriguchi, T., T. Sanada, and S. Yamaki. 1990. Seasonal fluctuations of some enzymes relating to sucrose and sorbitol metabolism in peach fruit J. Amer. Hort. Sci. 115:278-281.

Negro, F.B. and W.H. Loescher. 1979. Detection and characterization of sorbitol dehydrogenase from apple callus tissue. Plant Physiol. 64:6973.

Nelson, N. 1944. A photometric adaptation of the Somogyi method for the determination of glucose. J. Biol. Chem. 153:375-380.

Ricardo, C.P.P. and T. ap Rees. 1970. Invertase activity during the development of carrot roots. Photochemistry 9:239-247.

Ricardo, C.P.P. and D. Sovia. 1974. Development of tuberous roots and sugar accumulation as related to invertase activity and mineral nutrition. Planta 118:43-55.

Koe, J.H. 1934. A calorimetric method for the determination of fructose in blood and urine. J. Biol. Chem. 107: 15-22.

Schaffer A. A., B. Aloni, and E. Fogelman. 1987. Sucrose metabolism and accumulation in developing fruit of Cucumis. Photochemistry 26:18831887.

Turner, J.F. and D.H. Turner. 1975. The regulation of carbohydrate metabolism. Annu. Rev. Plant Physiol. 26: 159-186.

Webb, K.L. and J.W.A. Burley. 1962. Sorbitol translocation in apple. Science 137:766.

Yamaki, S., I. Kajiura. and N. Kakiuchi. 1979. Changes in sugars and their related enzymes during development and ripening of Japanese pear fruit (Pyrus serotina Rehder var. culta Rehder). Bul. Fruit Tree Res. Sta., Ministry Agr. For. Fisheries, Japan. A6:15-26.

Yamaki, S. and K. Ishikawa. 1986. Roles of four sorbitol related enzymes and invertase in the seasonal alteration of sugar metabolism in apple tissue. J. Amer. Soc. Hort. Sci. 111:134-137.

Yamaki, S. and T. Moriguchi. 1989. Seasonal fluctuation of sorbitol-reIated enzymes and invertase activities accompanying maturation of Japanese pear (Pyrus serotina Rehder var. culta Rehder) fruit. J. Jpn. Soc. Hort. Sci. 57:602-607. 